\title{
How Workspaces Influence Software Development? Preliminary Results of a Systematic Literature Review
}

\author{
Victor G. J. Costa ${ }^{1}$, Cesár França ${ }^{2}$ \\ ${ }^{1}$ CESAR School - Recife - PE - Brazil \\ ${ }^{2}$ Departamento de Computação \\ Universidade Federal Rural de Pernambuco (UFRPE) - Recife - PE - Brazil \\ vgjcosta@gmail.com, cesar@franssa.com
}

\begin{abstract}
This work brings to light the preliminary results of a literature review showing what physical elements of workspaces have been studied in software engineering, and what are their known impacts on software development performance. A systematic literature review has been conducted, covering a period of 16 years of publications in software engineering field. Seven dimensions of workspace factors were mapped and we present the impacts of these factors on elements of software development performance, such as communication and collaboration. This article evidences the fact that there is not a generally accepted best model for software development workspaces, and that there is still much room for investigation in this topic.
\end{abstract}

\section{Introduction}

An organization's workspace constitutes a powerful role that provides for its employees' ways to carry out their work activities [1]. The term "office layout" refers to how the arrangement and boundaries of workspaces are laid out. Office layout has a major social and economic importance for companies as employees spend a significant amount of time in the organization spaces to performing their roles [2]. A wide body of literature indicates and several studies from different disciplines haves already demonstrated that workplace's physical environments impacts on the perception, behavior, and performance of people at work [3].

The workspace should provide a way that maximize efficiency, enabling individuals to work with ease. It means that the workspaces needs to have characteristics that support individual and group interactions through spaces, furniture and technologies that enhances communication, coordination, and collaboration [4].

In the present study, we are interested in understanding the aspects related to the arrangement and layout of the workplace and the impact of this variables on the work of a software development related environment. The research reported in this article was guided by the following question: What aspects of office layout and arrangement could boost or hinder the performance of a software development environment?

This paper is organized in the following way: In the next section, a comprehensive literature review has been provided to support our findings. Section 3 presents the research method and details of the conducted systematic literature review. In Section 4, the results along with discussions are presented. In section 5, the conclusions, limitations and future work are addressed. 


\section{Literature Review}

In relation to an organization, an office refers to a specific area where individuals perform professional and business activities [5]. Traditionally and according to the literature, office types can be described as traditional (sometimes also referred as enclosed offices or cell offices), which are usually made up of private spaces delimited by walls, rooms and partitions that accommodates a small number of people or they can be described as open plan, that has no divisions and can accommodate a large number of individuals. In case of traditional workplaces, they have all the needs to do the job reunited at the same place.

In addition to the traditional and open plan types of offices, in the literature it is possible to find another term called agile workspaces or agile offices that have characteristics related to traditional and open plan types of office, but presents an another kind of work approach composed of a great variety of work configurations, such as: shared desks, informal spaces, relaxation rooms and contemplative spaces, so occupants can do their activities without a previously defined space [6].

Keeling et al [6] in their study compared agile workspaces with traditional types of office design such as open spaces and private environments to investigate the effects on privacy, crowding and satisfaction at work. The result has shown that agile workspaces is a distinct typology from open plan typologies and cellular offices.

Santos et al [7] still mentions the semi-open office type, that consists of placing sub-teams close to each other to promote face-to-face communication and that can be considered as an alternative when the adoption of the open plan type is not possible due to space limitations.

Rola et al [2] demonstrated an office layout model for agile IT projects managed by the Scrum framework. The proposed model is based on a cellular office layout inspired by honeycombs and composed by five cell types: conference cell, social/kitchen cell, chill out cell, development team cell and product owner cell. The model proposed by the authors restructured an existing open plan office space for the needs of an Agile project that follows the principles of the Scrum framework.

Another factor related to the work environment is the localization where a project or the team perform their activities. Co-located teams refers to individuals who are geographically close to perform their activities and has the benefit of direct, efficient and face-to-face communication, in addition to close customer proximity [8]. A distributed team is characterized by teams or most individuals in a project who are working geographically dispersed [9]. There is another approach related to team localization, called radical collocation, also known as war rooms, which is a strategy that involves putting the team (including a customer representative) in a single room [10].

Teasly et al [10] carried out a study to know if a radically collocated team lead to a higher productivity, shorter schedules, high costumer and team satisfaction and if there are any improvements in project performance. The results shown that, when people are radically collocated, there is a significant increase on productivity and timeliness due to continuous communication which improves consequently the team awareness. 
Clarke and O'Connor [11] proposed a reference framework to understand the characteristics of the situational factors that affect the software development process. The researchers conducted a case study through observation and interview with this reference framework in a small-sized company and concluded that the company has a current proper software process according to situational factors. The organization has not designed, redesigned or adapted its software process using the framework [12].

\section{Methods}

Due to the exploratory character of this work, a systematic literature review was conducted, an evidence-based method proposed by Kitchenham et al [13], for conduct software engineering studies, which was inspired by an approach for synthesizing evidence on medicine studies.

This theme demands research in a multidisciplinary approach, not only related to Software engineering. Therefore, to ensure a good starting point, we opted to perform an "ad-hoc" search in this preliminary study, to get a comprehensive map of the relevant terminology. In the next steps of this research, we plan to perform a systematic review with automated searches to enrich and complement the present findings.

We performed searches on the following engines: ACM Digital Library, IEEE Xplore and SCOPUS to find articles published between 2002 and 2018. We used the following words: "Agile", "Agile practices", "Software Engineering", "Software Development", "Workplace environment", "Physical settings", "Office layout", "Office type", "Office rearrangement", "Facilities Management" , "Office buildings", "Seating", "Crowding", "Occupant density", "Team collocation", "Dispersed teams" and "Situational factors".

Manual searches were performed on the bibliographic sources reported on this study. First, all the titles were read, and obvious irrelevant papers were removed. Then, an inclusion and exclusion process were applied for the potentially relevant papers, as described below.

Papers are eligible according to the inclusion criteria: (a) Studies related to the design and arrangement of the physical work environment, (b) Studies reporting the influence of the workplace and its constituents related to the performance and the success of the organization (c) Studies written in English (d) Studies published after 2002 and (e) The most recent version of the study.

We selected 17 relevant studies in the sources that we searched with the set of words listed previously, which then accounted as the final selection of studies.

The quality of the papers was simple evaluated using a set of criteria developed by the Centre for Reviews and Dissemination (CRD) Database of Abstracts of Reviews of Effects (DARE). The criteria are based on four questions: (a) Are the review's inclusion and exclusion criteria well described and appropriate? (b) Is the literature search likely to have covered all relevant studies? (c) Did the reviewers assess the quality/validity of the included studies? (d) Were the basic data/studies adequately described?.

Our findings are treated following the qualitative meta-summary method proposed by Sandelowski and Barroso [14]. This method consists in five techniques: 
extracting of findings, editing findings, grouping findings, abstracting findings and calculating frequency and intensity effect sizes.

\section{Results}

We identified a wide range of content, classifications and terminologies that are related to this approach, which may lead to a misinterpretation and also sometimes an inconsistent use of language in accordance to what related by Clarke and O'Connor [11], in their study.

Regarding to the work environment we considered two types. As physical we associated to people who are working in the same physical ambient. As virtual, we are considering the work that is related to a distributed approach and are supported by technology.

We have defined seven core dimensions. Below we explain each one of them.

Environment use practices: Under this dimension, there are characteristics that are related to practices and manners of how individuals occupies the workspace.

Layout pattern: Refers to the arrangement and how the boundaries of workspaces are laid out. Here, there where factors like Combi office, which according to Danielsson and Bodin [15] are characterized by having individual workstations in either an individual room or an open plan office.

Macro-environment: This dimension is defined by characteristics related to the whole workspace environment. It is composed by factors like the "Multiple teamwork environment" which refers to teams that are working on the same project in a specific office [2].

Micro-environment: This dimension treats about elements of office spaces, like spaces such as common areas, meeting spaces and others singular rooms, also there is a correlation with collocation practices.

Office design practices: Here, there are the factors that are related to characteristics and practices about the conception of office workspace design.

Software engineering practices: Under this dimension, there are factors linked to already known and explored software engineering practices that can be easily found on literature. "On-site customer", for example, brings a customer representative to work with the project team physically [8].

Support tool: This dimension is defined by both physical and digital tools that are used to perform the work on the organization.

Workplace characteristics could generate outcomes that impacts in a positive or in a negative manner different domains that are related to the work environment as presented in Figure 1. These domains are driven by a technical or an operational approach and are also related to human aspects. 


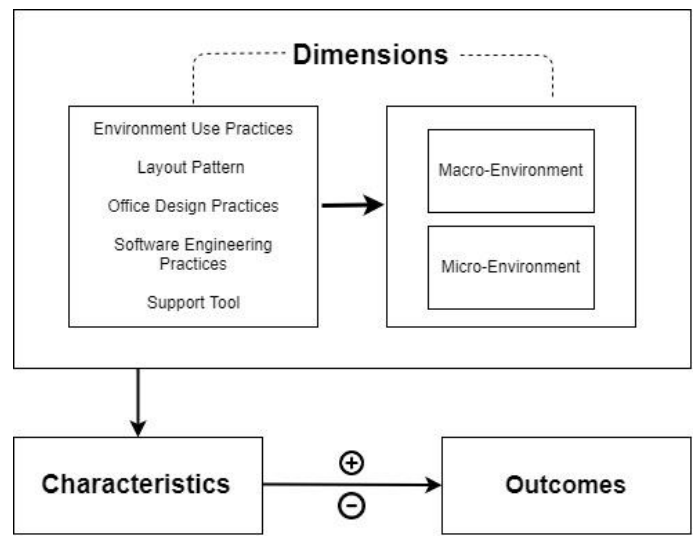

Figure 1. The relation between dimensions, characteristics and outcomes.

In relation to the characteristics, some of them were presented in the definition of the seven dimensions described above. To avoid a possible misinterpretation, we labeled the characteristics with same meaning in unique classifications, since different words were found in the literature for the same meaning. We have defined 77 characteristics, but due to the limitation on the size of this paper, we are presenting 10 of them in Table 1.

Table 1. List of characteristics

\section{Characteristics}

Cellular office / Collaborative spaces / Co-located agile team / Combi office / Common areas / Distributed agile team / Hoteling / On-site costumer / Open plan office / Traditional offices them.

Characteristics are grouped in 36 distinct groups. In Table 2 we are listing 10 of

Table 2. Groups of characteristics

\begin{tabular}{|c|}
\hline Groups of characteristics \\
\hline $\begin{array}{c}\text { Agile practices / Collocation / Common areas / Documentation / Face-to-face communication / } \\
\text { Flexibility / Half-cubicles / Individual workspaces / Information wall / Meeting spaces }\end{array}$ \\
\hline
\end{tabular}

We grouped our outcomes in 8 distinct groups of domains as follows:

Business: In general, this category is related to the operational environment of the organization, for example, financial and contractual considerations as payments, structure and material costs.

Communication: This classification is related to the whole communication process. Such as the mechanisms, tools, techniques, the quality and the effectiveness involved to transmit or receive a message.

Customer: Here are characteristics related to the customer involvement. Practices and actions to deliver the customer needs, to create value and to maintain or strengthen customer relations.

Management: Related to the characteristics under the domain of management's control of the project, that should provide the needs to perform the work.

Organization: We are considering here the factors that are associated with the organization environment such as the physical working arrangement and the facilities to 
house the project [11], including the space maintenance, coordination and operations, also the organizational structure and the worker availability (localization) through spaces.

Personnel: This classification is related to human aspects under the work environment. We are considering the human aspects of individual or group of individuals, including characteristics of their attitudes, behaviors, competencies and experiences under their efforts as part of an organization.

Product: Characteristics of the product or the service that are in development by the project that involves performance requirements, configuration and architecture demands, software and hardware capabilities, development, maintenance and deployment phases, reuse approach and required quality [11].

Prerequisites: This classification is regarding the needs to meet the project procedures and requirements in term of processes, standards, policies and common practices to ensure that the project is in accordance to its objectives.

Regarding to the groups of outcome domains we have defined above, we have identified 51 distinct types. In Table 3 we are listing 10 of them.

Table 3. List of Outcomes

\begin{tabular}{|l|}
\hline \multicolumn{1}{|c|}{ Outcomes } \\
\hline Clarify of ideas, problems and issues / Collaboration / Communication Quality / Coordination / \\
Individual work and problem-solving / Organizational structure / Performance / Shared knowledge and \\
information / Visual or acoustic distractions / Work planning \\
\hline
\end{tabular}

In Table 4 we are presenting our results in a limited view, since our findings resulted in considerable amount of data that are not possible to show completely due to limitation on the size of this paper. The complete table is available at the URL: bit.ly/HowWorkInfluSoftDev

Table 4. Sample of findings and correlations

\begin{tabular}{|c|c|c|c|c|c|c|c|}
\hline $\begin{array}{c}\text { Study } \\
\text { ref. }\end{array}$ & $\begin{array}{c}\text { Environme } \\
\text { nt Type }\end{array}$ & Dimension & $\begin{array}{c}\text { Group of } \\
\text { Characteristics }\end{array}$ & Characteristics & Effect & $\begin{array}{l}\text { Outcome } \\
\text { Category }\end{array}$ & Outcome \\
\hline Art.01 & Physical & $\begin{array}{c}\text { Software } \\
\text { engineering } \\
\text { practices }\end{array}$ & $\begin{array}{c}\text { Face-to-face } \\
\text { communication }\end{array}$ & $\begin{array}{c}\text { Face-to-face } \\
\text { communication }\end{array}$ & $\begin{array}{l}\text { Positive } \\
\text { Impact }\end{array}$ & $\begin{array}{c}\text { Communicati } \\
\text { on }\end{array}$ & $\begin{array}{l}\text { Reliability of } \\
\text { Information }\end{array}$ \\
\hline Art.02 & Physical & $\begin{array}{c}\text { Software } \\
\text { engineering } \\
\text { practices }\end{array}$ & $\begin{array}{c}\text { Team } \\
\text { characteristics } \\
\text { and abilities }\end{array}$ & $\begin{array}{l}\text { High skilled } \\
\text { team }\end{array}$ & $\begin{array}{l}\text { Positive } \\
\text { Impact }\end{array}$ & Personnel & Performance \\
\hline Art.03 & Physical & $\begin{array}{c}\text { Software } \\
\text { engineering } \\
\text { practices }\end{array}$ & Multitasking & $\begin{array}{l}\text { Team members } \\
\text { with different } \\
\text { work tasks }\end{array}$ & $\begin{array}{l}\text { Negative } \\
\text { Impact }\end{array}$ & Personnel & $\begin{array}{l}\text { Visual or } \\
\text { acoustic } \\
\text { distractions }\end{array}$ \\
\hline Art.04 & N/A & $\begin{array}{c}\text { Software } \\
\text { engineering } \\
\text { Practices }\end{array}$ & $\begin{array}{l}\text { On-site } \\
\text { costumer }\end{array}$ & $\begin{array}{l}\text { On-Site } \\
\text { costumer }\end{array}$ & $\begin{array}{l}\text { Positive } \\
\text { Impact }\end{array}$ & $\begin{array}{l}\text { Communicati } \\
\text { on }\end{array}$ & $\begin{array}{c}\text { Communication } \\
\text { quality }\end{array}$ \\
\hline Art.05 & Physical & $\begin{array}{l}\text { Layout } \\
\text { pattern }\end{array}$ & Open plan & $\begin{array}{l}\text { Open plan } \\
\text { office }\end{array}$ & $\begin{array}{l}\text { Negative } \\
\text { Impact }\end{array}$ & Personnel & $\begin{array}{l}\text { Individual work } \\
\text { and problem- } \\
\text { solving }\end{array}$ \\
\hline
\end{tabular}

\subsection{Discussions of results}

Layout pattern was the dimension that presented more data in our findings, even appearing in only 9 studies (52.94\%) and not being the dimension with most number of studies retrieved, it confirms the existence about a great concern by the researchers on 
the topic of how offices are designed and arranged. The most dominant group of characteristics was Open plan that appeared in 8 studies $(47,06 \%)$ and was the group of characteristics with the greater amount of data collected. When considering workplace strategies, open plan has become the preferred choice since its introduction in the 1960s and 1970s in north America [1]. Despite the well-known limitation related to employee accommodation, in our findings, Cellular office has presented only characteristics and outcomes with positive effects differently from the Open plan layout that has both positive and negative effects. According to Zhu [5], every office layout has its pros and cons. The best is the one who meets the organization and their employee needs.

As related to environment type, in all the 17 studies there are data related to the physical type of environment, in other hand, for the Virtual environment we have found data in only 8 studies $(47,06 \%)$. Personnel was the category of outcomes with the greater amount of data collected once we could retrieve data related to this category in all the 17 studies. It could be explained by the fact that the influence of human aspects on organization's performance it's a subject that interests' researchers and companies from diverse areas. Collaboration along with Visual and acoustic distractions were the two most general dominant outcomes in our findings. They were both part of the Personnel outcome category. In case of Collaboration, it was possible to find data in 11 studies $(64,71 \%)$ and for Visual and acoustic distractions we could found data in 8 studies (47,06\%). In case of Visual and acoustic distractions, despite expectations, our findings demonstrated more outcomes with positive effect $(62,5 \%)$ than negative $(37,5 \%)$ in relation to the total amount of data.

\section{Conclusion}

The amount of data collected shown that there is still much room for investigation, once the 17 selected studies generated considerable results in accordance with the set of variables that we have defined and with the aims of this study. Also, the discussions presented in this paper, point to the need for deeper analysis regarding to our findings, as they were performed with an initial view related to this subject of study.

Once the present paper was conducted as a preliminary study our data and analysis may be limited. Future research is required to expand our findings and to bring new insights. As our findings were supported by a manual search approach in this study, one of the next objective is to perform a systematic review with automated searches to enrich and complement our research.

\section{References}

[1] M. C. Davis, D. J. Leach and, C. W. Clegg (2011). The Physical Environment of the Office: Contemporary and Emerging Issues. International Review of Industrial and Organizational Psychology, Vol. 26, 193-235.

[2] Paweł Rola, Dorota Kuchta, and Dominika Kopczyk (2016). Conceptual model of working space for Agile (Scrum) project team. Journal of Systems and Software, Vol 118, 49-63.

[3] Y. Hua, V. Loftness, R. Kraut, and K. M. Powell (2010). Workplace Collaborative Space Layout Typology and Occupant Perception of Collaboration Environment. Environment and Planning B: Planning and Design, 37(3), 429-448. 
[4] Deepti Mishra, Alok Mishra, and Sofiya Ostrovska (2012). Impact of physical ambiance on communication, collaboration and coordination in agile software development: An empirical evaluation. Information and Software Technology, 54(10), 1067-1078.

[5] Lihong Zhu (2013). The physical office environment in technical services in ARL libraries. Library Collections, Acquisitions, and Technical Services 37, Issues 1-2, $42-55$.

[6] Trevor Keeling, Derek Clements-Croome, and Etienne Roesch (2015). The Effect of Agile Workspace and Remote Working on Experiences of Privacy, Crowding and Satisfaction. Buildings, 5(3), 880-898.

[7] Viviane Santos, Alfredo Goldman, Eduardo Guerra, Cleidson De Souza, and Helen Sharp (2013). A pattern language for inter-team knowledge sharing in agile software development. Proceedings of the 20th Conference on Pattern Languages of Programs (PLoP '13), Art. 20, The Hillside Group, USA.

[8] Markus Hummel, Christoph Rosenkranz, and Roland Holten (2015). The Role of Social Agile Practices for Direct and Indirect Communication in Information Systems Development Teams Information Systems Development Teams. Vol. 36, Art. 15.

[9] Helen Sharp, Rosalba Giuffrida, and Grigori Melnik (2012). Information Flow within a Dispersed Agile Team: A Distributed Cognition Perspective. In Agile Processes in Software Engineering and Extreme Programming. XP (2012). Lecture Notes in Business Information Processing, Vol 111. Springer, Berlin.

[10] Stephanie D. Teasley, Lisa A. Covi, M. S. Krishnan, and Judith S. Olson (2002). Rapid Software Development Through Team Collocation. IEEE Transactions on Software Engineering. 28(7), 671-683.

[11] Paul M. Clarke and Rory V. O'Connor (2012). The situational factors that affect the software development process: Towards a comprehensive reference framework. Information and Software Technology, 54(5), 433-447.

[12] Görkem Giray, Murat Yilmaz, Rory V. O’Connor, and Paul M. Clarke (2018). The Impact of Situational Context on Software Process: A Case Study of a Very SmallSized Company in the Online Advertising Domain. Systems, Software and Services Process Improvement. Proceedings of the 25th European Conference, (EuroSPI 2018), Bilbao, Spain, Vol. 896, 28-39, Bilbao, Spain.

[13] B. A. Kitchenham, T. Dyba, and M. Jorgensen. (2004). Evidence-based software engineering. Proceedings of the 26th International Conference on Software Engineering, (ICSE '04), IEEE Computer Society, Washington DC, USA, 2004, 273-281.

[14] M. Sandelowski and, J. Barroso (2007). Handbook for Synthesizing Qualitative Research, Springer Publishing Company, New York.

[15] C. B. Danielsson and L. Bodin (2008). Office Type in Relation to Job Satisfaction Among Employees. (2008), 636-668. 